\title{
EFFECT OF ATRAZINE AND GLYPHOSATE ON THE REPRODUCTIVE SYSTEM OF FEMALE RATS: HISTOLOGICAL AND IMMUNOHISTOCHEMICAL STUDIES
}

\author{
WALAA A MOSELHY ${ }^{1}$; TAGHREED M. NABIL ${ }^{2}$; BR ABDEL-HALIM ${ }^{3}$ and \\ NERMEEN A. HELMY \\ ${ }^{1}$ Department of Forensic Medicine and Toxicology, Faculty of Veterinary Medicine, Beni-Suef University, Egypt. \\ ${ }^{2}$ Department of Cytology and Histology, Faculty of Veterinary Medicine, Beni-Suef University, Egypt. \\ ${ }^{3}$ Department of Theriogenology, Faculty of Veterinary Medicine, Beni-Suef University, Egypt. \\ ${ }^{4}$ Department of Physiology, Faculty of Veterinary Medicine, Beni-Suef University, Egypt.
}

Received: 31 December 2015; Accepted: 27 January 2016

\begin{abstract}
Atrazine and Glyphosate are widely used herbicides in Egypt for the control of broad leaf and grassy weeds in agricultural crops. In this study, we aimed to investigate the deteriorative effects of both previous herbicides on reproductive system of female rats. for this purpose, forty five female albino rats aged 90 days (sexually mature), body weight about $180 \pm 20 \mathrm{~g}$ per animal were divided into three groups: Group1: kept without any treatment and considered as control. Group2: were orally administered atrazine $300 \mathrm{mg} / \mathrm{kg}$ bw /day. Group3: were orally administered glyphosate $500 \mathrm{mg} / \mathrm{kg}$ bw /day. The duration of the experiment was lasted for 45 days; five animals were sacrificed at 15 and 30 days of treatment from each group. For recovery, five animals from each group remain 15 days without treatment served as withdrawal groups. Our results demonstrate that these chemicals cause reproductive toxicity in exposed female rats include disruption of the hormones, disturbance of estrous cycle and histopathological changes in ovaries and uterus with decreasing in VEGF expression. Glyphosate had less deteriorating effect on fertility parameters of the exposed female rats than atrazine as well as the natural recovery rate after withdrawal is higher in glyphosate than atrazine.
\end{abstract}

Key words: Atrazine, glyphosate, rat, VEGF immunohistochemistry, estrogen, progesterone.

\section{INTRODUCTION}

In Egypt, the two herbicides, atrazine and glyphosate are usually used. The glyphosate-based herbicides are most often applied and their utilization increased in the period of 2000-2004 (Battaglin et al., 2005). Atrazine (ATR) (2-chloro-4-(ethylamine)-6(isopropyla-mine)-s-triazine, ATR) is an s-triazine herbicide inhibiting photo system II that has been used extensively worldwide to control pre- and postemergence broad leaved and grassy weeds in major crops (Lasserre et al., 2009). ATR has been shown to inhibit both the luteinizing hormone (LH) surge and pulsatile LH release in exposed rats (Foradori et al., 2009). Glyphosate is extensively used worldwide, topping lists of agricultural herbicide. It is abroadspectrum, post emergence herbicide (Schonbrunn et al., 2001). Glyphosate is generally applied as part of a formulated product, the most widely used of which are the Roundup herbicides. Glyphosate and Roundup are also extensively used as domestic and urban-areas weed-killers (EPA, 2011) and it is known to strongly adsorbed to soil, where it is subjected to microbial degradation. Angiogenesis is an essential process in

Corresponding author: Dr. TAGHREED M NABIL

E-mail address: tagh_mhm@yahoo.com

Present address: Department of Cytology and Histology, Faculty of Veterinary Medicine, Beni-Suef University, Egypt female reproductive organs (Modlich et al., 1996) which regulated by vascular endothelial growth factor

(VEGF). It acts as a potent angiogenic factor that stimulates vascular permeability during the normal ovarian cycle (Kamat et al., 1995), endometrial development and embryonic implantation (Nardo, 2005 and Demirm et al., 2006).

The aim of the present study was designed to compare the effect of atrazine and glyphosate exposure on female reproductive system and their influencing on VEGF expression in ovarian and uterine tissues. In addition to, study recovery after withdrawal of both herbicides.

\section{MATERIALS AND METHODS}

\section{Animals}

Forty five female albino rats aged 90 days (sexually mature), body weight about $180 \pm 20 \mathrm{~g}$ per animal were used. The rats were obtained from the Breeding Unit of the Egyptian Organization for the Biological and Vaccine Production. The animals were acclimated to the central laboratory of the Faculty of Veterinary Medicine, Beni Suef for 2 weeks prior to 
the start of the experiments at suitable conditions of temperature and light. Animals were housed individually in polycarbonate cages in a room with controlled temperature $\left(24 \pm 1^{\circ} \mathrm{C}\right)$ and humidity $(50 \pm$ $5 \%$ ), and a $12 \mathrm{~h}$ light/dark cycle. The study was conducted in compliance with the law of the humane treatment and management of animals according to All Life In a Viable Environment (ALIVE, Law No. 105,1973 revised in 2000) in Japan.

\section{Chemicals}

Atrazine (6-chloro-N-ethylamino-Nisopropylaminos-1,3,5-triazine-2,4 diamine)

Commercial name (Gesaprim 80\%), purchased from Singenta Company, Switzer Land, imported by El Nasr Company.

\section{Glyphosate (glycine Isopropylammonium)}

Commercial name (Bellarsato 48\%) purchased from Bellarkem-Shanghai-China, imported by International Company, El Giza, Egypt.

\section{Experimental design}

The rats used in the present study were assigned randomly $(n=15)$ to three groups: Group1: Animals of this group had been kept as normal without any treatment and considered as controls. Group2: They were orally administered atrazine $300 \mathrm{mg} / \mathrm{kg}$ bw/day (five days per week) according to (Mc Mullin et al., 2004), which represented as 1/10 LD50. Group3: They were orally administered glyphosate $500 \mathrm{mg} / \mathrm{kg}$ bw /day (five days per week) according to (Chan et al., 1992), which represented as 1/10 LD50. Clinical signs and mortalities were observed in treated rats twice daily, body weight and food consumption were measured twice a week. The duration of the experiment was lasted for 45 days; five animals were sacrificed from each group at 15 and 30 days of treatment. For recovery, five animals from each group remain 15 days without treatment and served as withdrawal groups.

\section{Assessment of vaginal cycles}

The estrous cycles were monitored by a method described by Marcondes et al. (2002), where vaginal smear was collected with a glass pipette filled with $10 \mathrm{ml}$ of normal saline $(\mathrm{NaCl} 0.9 \%)$. The vaginal fluid was placed on clean glass slide and observed under a light microscope at $\mathrm{x} 10 \mathrm{O}$ and $\mathrm{x} 400$ magnification. The three types of cells recognized were epithelial, cornfield cells and leucocytes. The proportions among these cells were used to determine the estrous phases. The vaginal smear was classified as either diestrous (predominance of leukocytes and a few scattered cornfield epithelial cells), proestrous (predominance of round, clumped, nucleated epithelial cells that may be dispersed or clumped), or estrous (all cornified cells). Only those females exhibiting regular 4-d estrous cycles for a period of 2 weeks were subsequently included in the study. Daily smears were also taken immediately prior to treatment and continued throughout the experiment.

\section{Hormonal assays}

Blood samples were collected from the retro-orbital venous plexus by means of clean heparinized micro capillary tubes, after centrifugation the serum was separated and hormonal assay for estrogen and progesterone serum levels was done using estradiol and progesterone immunoassay kit (Medix Biotech Inc., USA).

\section{Histological studies}

Collected samples from ovaries and uterus were fixed in $10 \%$ buffered formalin. The samples were trimmed in order to obtain a size of one cubic $\mathrm{cm}$. The samples were subjected to classical histological procedures of dehydration, clearing and paraffin embedding. Serial sections 4-6 $\mu \mathrm{m}$ cut and subjected to Hematoxylin and Eosin stain for general histological studies. All the fore mentioned fixatives and stains as outlined by (Bancroft and Gamble, 2008). Ovarian and uterine sections were immunohistochemically stained for vascular endothelial growth factor (VEGF). The stained sections were examined by binuclear research microscope (Leica, Hannover, Germany) attached with digital camera (Canon, Tokyo, Japan).

\section{Immunohistochemical Study}

The anti-rat VEGF primary antibody and lab vision kits suitable for immunohistochemical staining of formalin-fixed paraffin embedded sections using the avidin-biotin-peroxidase complex technique. Sections from both ovarian and uterine tissues were dewaxed in in xylene, rehydrated and pretreated with $3 \%$ hydrogen peroxide for blocking endogenous peroxidise activity. Microwave-assisted antigen retrieval was then performed for 20 minutes. Sections were incubated overnight at $40^{\circ} \mathrm{C}$ with the anti-rat VEGF polyclonal antibody. After washing with PBS, sections were incubated with biotinylated secondary antibody (Lab Vision Kits) and then with sterpt avidin -peroxidase conjugate. Sections were then washed with PBS and incubated with diaminobenzidine (DAB) for 5 minutes and counterstained with Mayer's hematoxylin. Cells positive VEGF showed cytoplasmic brown deposits. Negative control sections were obtained by omission of incubation with the primary antibody (Bancroft and Cook, 1994; Frost et al., 2000).

\section{Statistical analysis}

All data were analyzed using one way analysis of variance (One way ANOVA) followed by Duncan test using SPSS version 16.0 statistical software (SPSS, Inc, Chicago, IL.2007). 


\section{RESULTS}

\section{Gross observation}

All treated rats did not show any signs of toxicity or mortality. Females that treated with atrazine (15 and 30 days) exposure showed irregular estrous cycle with prolonged diestrus, while rats that treated with glyphosate showed irregular estrous cycle only after 30 days exposure in comparison with control. After stoppage of atrazine exposure (15 days) the estrous cycle remain irregular while in glyphosate the estrous cycle become regular after cessation of treatment in withdrawal group (15 days).

\section{Hormonal assays}

Table 1: Showing serum estrogen and progesterone levels $(\mathrm{pg} / \mathrm{ml})$ in control as well as treated rats $(\mathrm{Mean} \pm \mathrm{SE})$.

\begin{tabular}{ccc}
\hline Treatment & Estrogen & Progesterone \\
\hline Control & $62.3 \pm 0.49$ & $35.2 \pm 3.2$ \\
\hline Atrazine 15 days & $48.5 \pm 1.18^{*}$ & $20.8 \pm 1.8^{*}$ \\
\hline Atrazine 30 days & $36.9 \pm 1.5^{*}$ & $18.6 \pm 2.3^{*}$ \\
\hline Atrazine (15 day withdrawal) & $35.4 \pm 1.4^{*}$ & $30.6 \pm 2.5^{*}$ \\
\hline Glyphosate 15 days & $61.1 \pm 1.3$ & $33.8 \pm 2.5$ \\
\hline Glyphosate 30 days & $33.9 \pm 1.6^{*}$ & $22.0 \pm 1.9^{*}$ \\
\hline Glyphosate (15 day withdrawal) & $61.6 \pm 1.4$ & $34.4 \pm 4.5$ \\
\hline
\end{tabular}

$\mathrm{N}=5$, values with superscript $*$ were significantly different at $<0.05$

Data in the above table, showed that atrazine treatment for 15 and 30 days caused significant decrease in estrogen and progesterone levels, as compared with control, these levels did not returned to normal following natural recovery (15 days withdrawal). On the other side, glyphosate treatment for 30 days caused significant decrease in estrogen and progesterone levels while after natural recovery (15 days withdrawal) they returned to its normal level.

Histological and immunohistochemical results:

a) Ovarian tissue: Microscopical examination of H\&E stained sections of control rat ovary revealed that its cortex occupied by different developmental stages of healthy growing follicles, new postovulatory corpora lutea and old ones from previous cycle and few atretic follicles (plate 1, fig.1). The ovarian medulla composed of connective tissue and large sized blood vessels. The ovarian germinal epithelium lined with flattened cells. Primordial follicles located peripherally just beneath the tunica albuginea. Secondary follicles with multilayer of mitotic follicular cells, well - distinct zona pellucida were seen. Well-developed corpora lutea were surrounded by connective tissue capsule housing blood capillaries (plate 1, fig.2). Marked histological changes were observed in rat ovaries exposed to atrazine for 15 days including disappearance of any stage of growing follicles and newly formed corpora lutea. Most of antral follicles manifested by different forms of atresia as degeneration or complete lysis of the oocyte and disorganization and pyknosis of granulosa cells, also, stratifications and invaginations of ovarian germinal epithelium (plate 1, fig. 3\&4). Progressive histological alterations were noticed in the ovary of rats received atrazine for 30 days which manifested by presence of multiple cystic and atretic follicles (plate 1, fig. 5). In rats were natural recovery after atrazine exposure, mild improvement was shown in the examined ovaries which exhibited by reappearance of healthy growing follicles while the newly formed corpora lutea still absent (plate 1, fig. $6)$. In glyphosate treated rats for 15 days, no marked histological changes were recorded in the examined ovarian sections. Well-developed corpora lutea and growing follicles were seen (plate 1, fig. 7). While pronounced histological alterations were seen after glyphosate exposure for 30 days including complete absence of newly formed corpora lutea while the existing ones appeared in regressed form in addition to atretic antral follicles (plate 1, fig. 8). Examined ovarian sections of naturally recovered rats after glyphosate exposure for 30 days showed great improvement and regained the normal architecture (plate 1, fig. 9).

In immmunohistochemical study, the control ovarian sections showed strong cytoplasmic VEGF staining reaction within the ovarian germinal epithelium, the granulosa cells and thecal cells of the ovarian follicles, stromal cells and endothelial cells of blood vessels. Also, the luteal cells of the newly formed corpora lutea exhibited intense positive reaction while moderate or negative immunoreactivity was shown in 
the previously formed corpora lutea (plate 2, fig. $1 \& 2)$.

The sections of atrazine treated rats either for 15 or 30 days showed negative VEGF immunoreactivity (plate 2, fig. 3). While mild improvement was seen in naturally recovered rats from atrazine. VEGF was moderately expressed in the same ovarian distribution of the control rats (plate 2, fig. 4). In glyphosate treated rats for 15 days, the ovarian sections showed intense positive VEGF immunoreactivity as similar to the control group (plate 2, fig. 5). On the other hand, negative VEGF immunoractivity was recognized in the ovarian sections of glyphosate treated rats for 30 days (plate 2, fig.6). Great improvement was seen in the ovarian sections of naturally recovered rats after glyphosate treatment for 30 days which became similar to the control group (plate 2, fig.7).

b) Uterine tissue: Microscopical examination of uterine tissue sections stained with $\mathrm{H} \& \mathrm{E}$ showed that the endometrium of control rat lined with simple columnar epithelium with oval and vesicular nuclei. Numerous tubular and branched endometrial glands were embedded in intact highly cellular endometrial stroma and lined with simple cuboidal or columnar cells (plate 3 , fig. 1 ).

In the atrazine treated group for 15 days, pronounced histological changes were seen including vacuolation and pyknosis of the affected endometrial surface epithelium, dilatation of endometrial glands with vacuolated and desquamated lining epithelium, infiltration of inflammatory cells in the endometrial stroma and dilated and congested blood vessels (plate 3 , fig. 2). The atrazine treated group for 30 days, progressive endometrial degenerative changes were noticed as severe desquamation, stratifications in some areas of affected surface epithelium with pyknosis and decreasing in the height. Marked depletion in the uterine glands and pyknotic stromal cells were observed (plate 3, fig.3). In naturally recovered group from atrazine, mild improvement was noticed in the examined sections. The endometrial surface epithelium regained its regularity but still exhibited decreasing in the height with some degeneration. The uterine glands increased and appeared normal as well as new developing glands were identified. The endometrial stroma regained its normal architecture (plate 3, fig.4). The uterine tissue of treated rats with glyphosate for 15 days revealed that the endometrial surface epithelium was not affected, while the endometrial stroma was slightly edematous and infiltrated with massive inflammatory cells. The lining epithelium of the affected uterine glands showed vacuolations and pyknosis (plate 3, fig.5). Degenerative changes were progressed in the examined sections of glyphosate treated rats for 30 days. The endometrial surface epithelium became affected with irregularity in the height ranged from columnar to cuboidal till reach squamous cells with flattened and pyknotic nuclei. Moreover, marked reduction in the uterine glands and most of them appeared degenerated or atrophied (plate 3, fig.6). While pronounced improvement was seen in sections of the rats which were left for natural recovery from glyphosate. They regained the normal uterine architecture (plate 3, fig.7).

In immunohistochemical study, the control rats showed strong positive cytoplasmic VEGF immunostaining within the endometrial surface epithelium and glandular epithelial cells. Also, the endothelial cells and endometrial stromal cells exhibited strong reaction (plate 4 , fig. 1). In atrazine treated rats for 15 days, majority of the endometrial surface and glandular epithelium still showed strong VEGF immunoreaction. While the endometrial stromal and endothelial cells exhibited very weak or nearly negative reaction (plate 4, fig. 2). Obvious negative VEGF immunoreaction was spread throughout the uterine architecture in rat treated with atrazine for 30 days (plate 4, fig. 3). Moderate improvement in the uterine sections was observed in the naturally recovered rats from atrazine. The endometrial stromal and endothelial cells were VEGF moderately reacted while the endometrial surface and glandular epithelial cells still exhibited weak to negative immunoreactivity (plate 4, fig. 4). In glyphosate treated rats for 15 days, the uterine sections appeared with strong positive VEGF immunoreactivity as similar to the control group (plate 4, fig. 5). Such reaction became weak or negative in both the endometrial surface and glandular epithelial cells while the stromal and endothelial cells were not affected in rats exposed for glyphosate for 30 days (plate 4, fig. 6). However, the uterine sections showed positive cytoplasmic expression of VEGF almost reaching to the control group (plate 4 , fig. 7 ). 
Plate 1: Showing ovarian tissue of control and treated rats stained with $\mathrm{H} \& \mathrm{E}$.
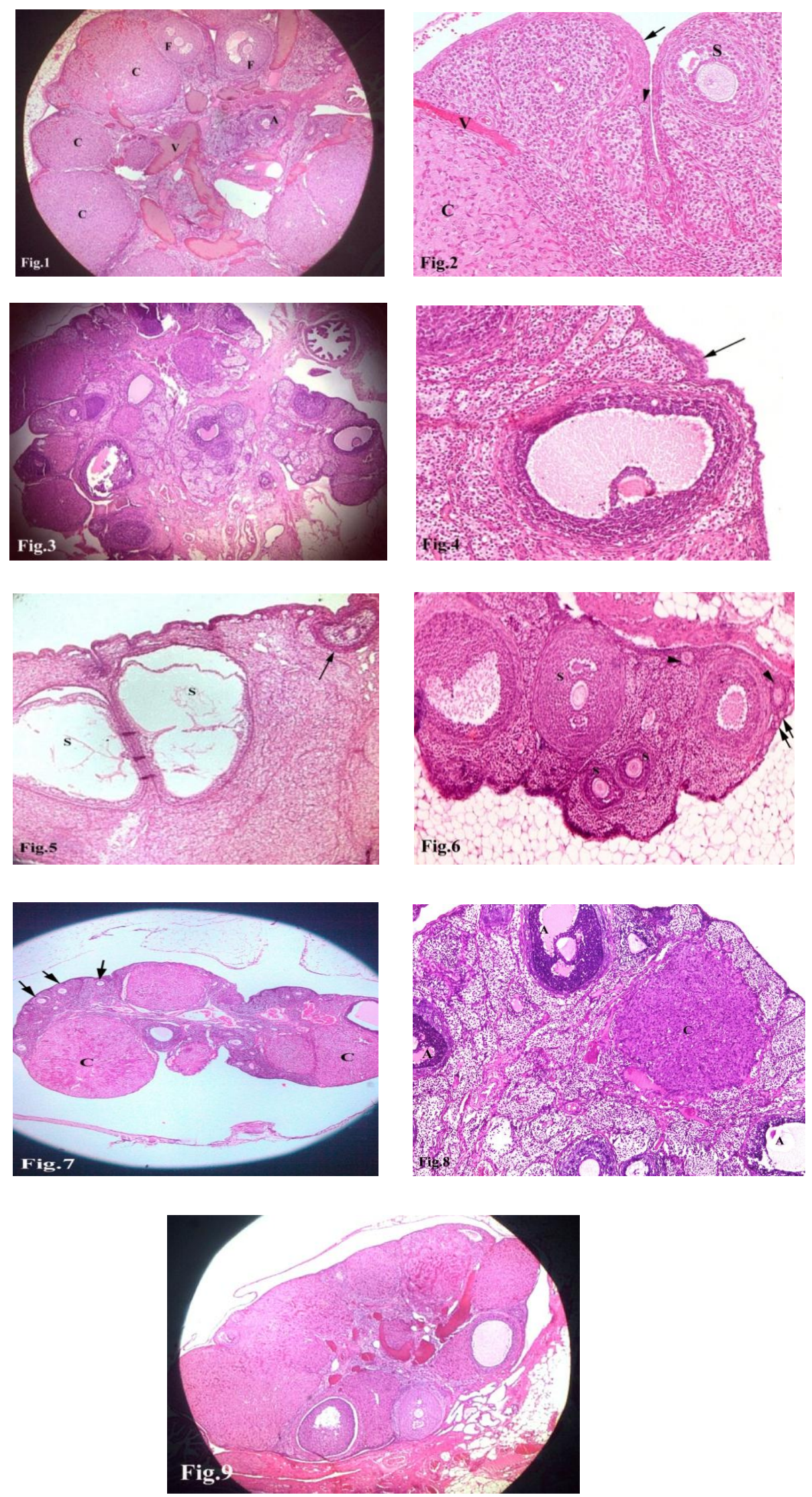
Plate 2: Showing ovarian tissue of control and treated rats stained with avidin-biotin peroxidase technique.
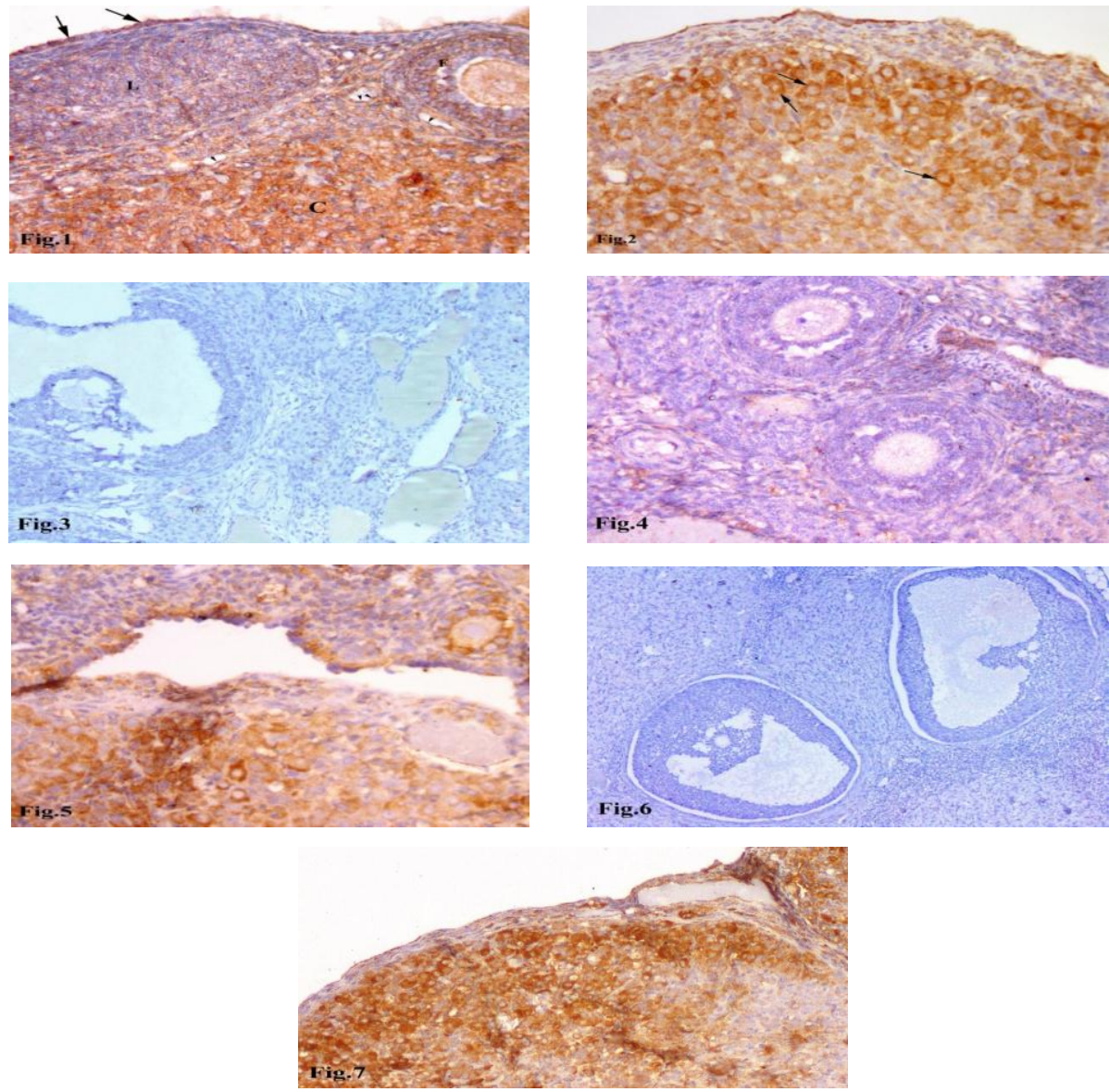

Plate 3: Showing uterine tissue of control and treated rats stained with $\mathrm{H} \& \mathrm{E}$.
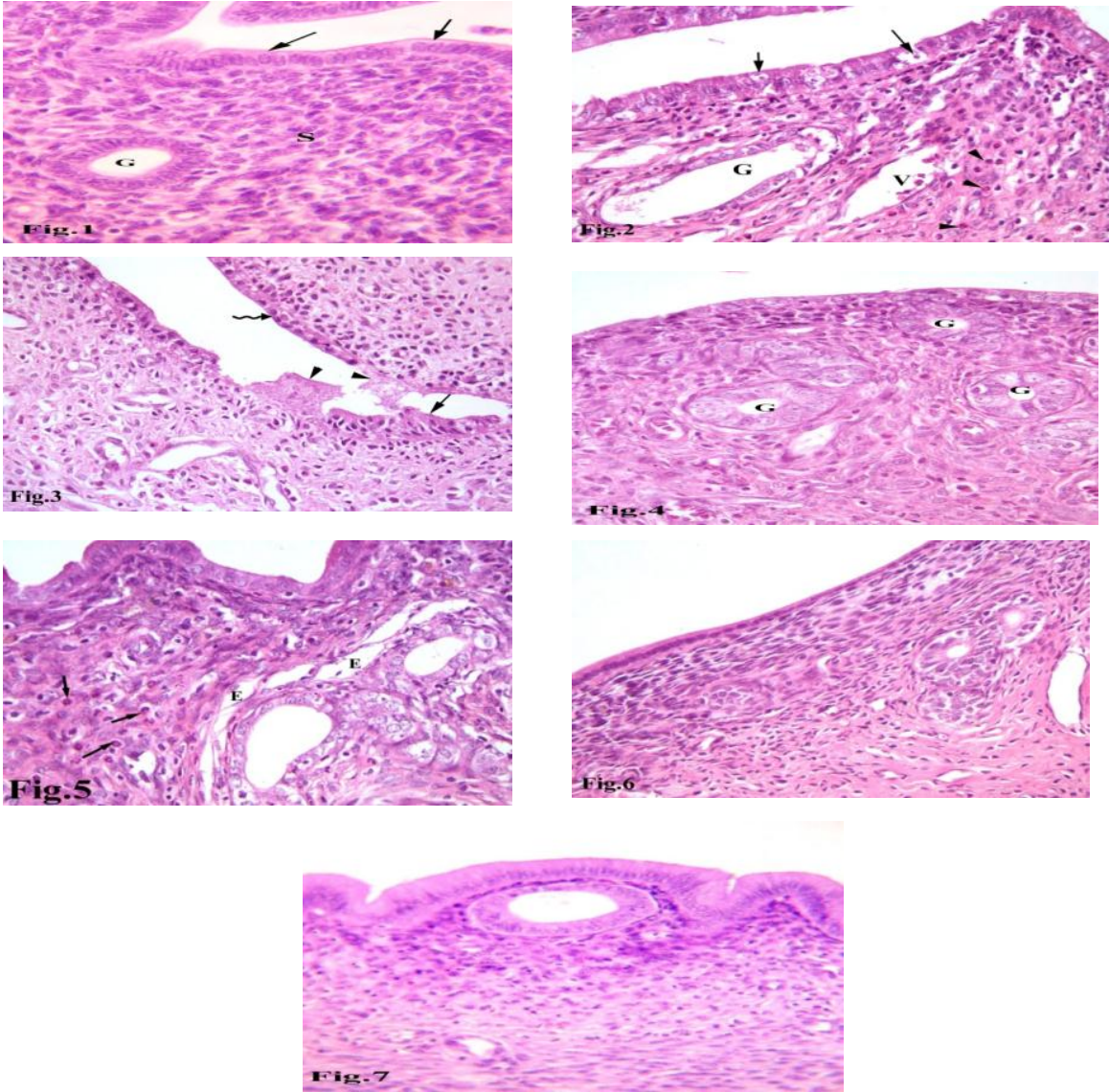
Plate 4: Showing uterine tissue of control and treated rats stained with avidin-biotin peroxidase technique.
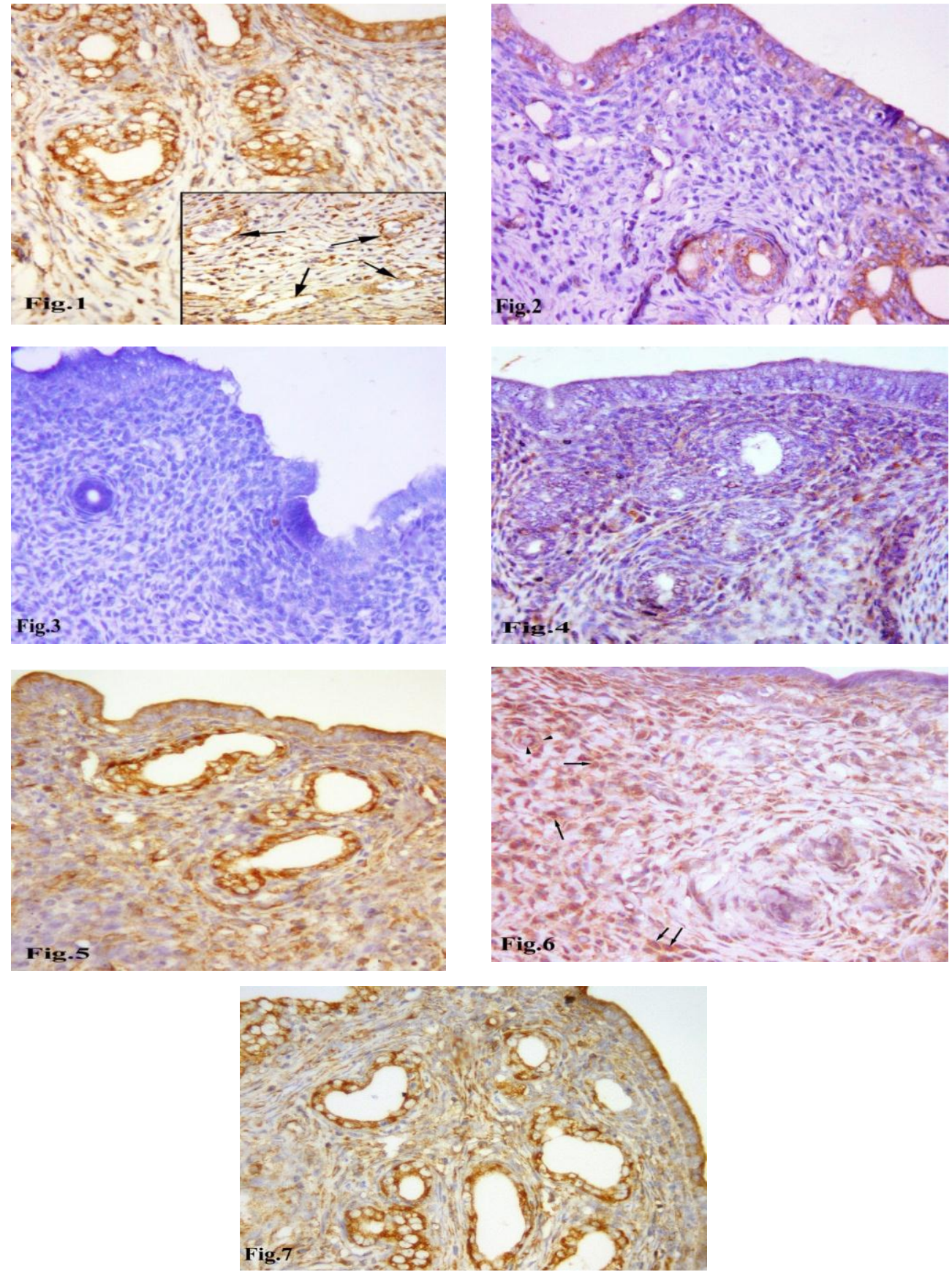

\section{List of legends:}

Plate 1: Ovarian tissue of control and treated rats stained with $\mathrm{H} \& \mathrm{E}$.

Fig. 1: A photomicrograph of control rat ovary showing the outer ovarian cortex occupied by many newly formed corpora lutea (c), different developmental stages of ovarian follicles $(\mathrm{F})$, few atretic follicles (A) and large sized blood vessels $(V)$ in the ovarian medulla. $H \& E, 40 x$.

Fig. 2: A higher magnification of control rat ovary showing ovarian surface epithelium with flattened cells ( an arrow), primordial follicles (an arrowhead), secondary follicle (S) and well developed corpus luteum (C) surrounded by connective tissue capsule housing blood vessels (V). H\&E, 400x.

Fig. 3: A photomicrograph of rat ovaries treated with atrazine for 15 days showing disappearance of any developmental stages of growing follicles and newly formed corpora lutea. H\&E, 40x.

Fig. 4: A higher magnification of (fig. 3) showing marked stratification and invaginations of the ovarian surface epithelium (an arrow). Notice, atretic antral follicle surrounded by degenerated and pyknotic granulosa cells. $\mathrm{H} \& \mathrm{E}, 400 \mathrm{x}$. 
Fig. 5: A photomicrograph of rat ovary treated with atrazine for 30 days showing ovarian cysts (S) and atretic follicles (an arrow). H\&E, 100x.

Fig. 6: A photomicrograph of rat ovary naturally recovered from atrazine exposure showing reappearance of different stages of growing follicles as primordial (arrows), primary follicles (arrowheads), and secondary follicles (S). Notice, absence of any newly formed corpora lutea. H\&E, 100x.

Fig. 7: A photomicrograph of rat ovary received glyphosate for 15 days showing normal ovarian architecture as newly formed corpora lurtea (C) and different developmental stages of ovarian follicles (arrows). H\&E, 40x.

Fig. 8: A photomicrograph of rat ovary received glyphosate for 30 days showing regressed corpora lutea $(\mathrm{C})$ and numerous atretic follicles (A). H\&E, 200x.

Fig. 9: A photomicrograph of rat ovary naturally recovered from glyphosate exposure for 30 days showing great improvement and become similar to the control group. H\&E, 40x.

Plate 2: Ovarian tissue of control and treated rats stained with avidin- biotin Peroxidase technique

Fig. 1: A photomicrograph of control rat ovary showing strong positive immunostaining reaction within ovarian surface epithelium (arrows), cells of ovarian follicles (F) and endothelial cells (arrowheads). Notice, weak or negative VEGF immunoreaction within the previously formed corpora lutea (L) while intense reaction within the newly formed ones (C).400x.

Fig. 2: A higher magnification of the newly formed corpus luteum of control rat ovary showing strong positive VEGF reaction in the luteal cells (arrows). 1000x.

Fig. 3: A photomicrograph of rat ovaries treated with atrazine for 15 days showing negative VEGF immunoreactivity. 200x.

Fig. 4: A photomicrograph of rat ovary naturally recovered from atrazine after exposure for 30 days showing moderate VEGF immunoreactivity in most of ovarian architecture. 400x.

Fig. 5: A photomicrograph of rat ovary received glyphosate for 15 days showing positive VEGF staining reaction. $400 \mathrm{x}$.

Fig. 6: A photomicrograph of rat ovary received glyphosate for 30 days showing negative VEGF immunoreactivity.200x

Fig. 7: A photomicrograph of rat ovary after natural recovery from glyphosate treatment for 30 days showing great improvement with strong positive VEGF immunoreactivity as in control group. $200 x$
Plate 3: Uterine tissue of control and treated rats stained with $\mathrm{H} \& \mathrm{E}$.

Fig. 1: A photomicrograph of control rat uterus showing normal architecture including endometrial surface epithelium with columnar cells (arrows), endometrial glands (G) and endometrial stromal cells (S).H\&E, 400x.

Fig. 2: A section of rat uterus exposed to atrazine for 15 days showing vacuolated and pyknotic endometrial surface epithelium (arrows), dilated endometrial glands with desquamated epithelium $(\mathrm{G})$, dilated and congested blood vessels (V) and infiltrated inflammatory cells in the endometrial stroma (arrowheads). H\&E, 400x.

Fig. 3: A section of rat uterus exposed to atrazine for 30 days showing stratified (arrow), desquamated (arrowheads) and pyknotic (wavy arrow) endometrial surface epithelium with decreasing in the height, depleted uterine glands and pyknotic endometrial stromal cells. H\&E, 400x.

Fig. 4: A section of uterus of naturally recovered rats from atrazine exposure for 30 days showing moderate improvement with normal and new developing endometrial glands (G). H\&E, 400x.

Fig. 5: A section of rat uterus exposed to glyphosate for 15 days showing moderate alterations including edematous patches (E) and inflammatory cells in the endometrial stroma (arrows). H\&E, 400x.

Fig. 6: A section of rat uterus exposed to glyphosate for 30 days showing irregularity in the height of surface epithelium, degenerated and atrophied uterine glands surrounded by pyknotic stromal cells. H\&E, 400x.

Fig. 7: A section of uterus of naturally recovered rats from glyphosate treatment for 30 days showing marked improvement in the architecture as similar to the control group. H\&E, 400x.

Plate 4: Uterine tissue of control and treated rats stained with avidin- biotin Peroxidase technique

Fig. 1: A photomicrograph of control rat uterus showing strong positive VEGF immunoreactivity within the surface, glandular epithelial cells and stromal cells. Inbox figure showing strong VEGF in endothelial cells (arrows). 400x.

Fig. 2: A photomicrograph of rat uterus treated with atrazine for 15 days showing moderate to weak VEGF immunoreaction in the stromal and endothelial cells, strong reaction in surface and glandular epithelial cells. 400x.

Fig. 3: A photomicrograph of rat uterus treated with atrazine for 30 days showing negative VEGF immunoreactivity in all uterine architecture. 400x. 
Fig. 4: A section of uterus of naturally recovered rats from atrazine treatment for 30 days showing moderate VEGF reaction in the stromal cells. 400x.

Fig. 5: A section of rat uterus exposed to glyphosate for 15 days showing strong positive VEGF immunoreaction distributed as similar to the control group.400x.

Fig. 6: A section of rat uterus exposed to glyphosate for 30 days showing negative VEGF immunoreaction within the surface epithelium while positive reaction in most of the stromal cells (arrows) and endothelial cells (arrowheads). 400x.

Fig. 7: A section of uterus of naturally recovered rats from glyphosate exposure for 30 days showing pronounced improvement by returning the strong positive VEGF immunoreaction throughout the uterine architecture as similar to the control group. 400x.

\section{DISCUSSION}

Results of the current study revealed that there was a significant decrease in serum estrogen level in atrazine treated groups after $15 \& 30$ days of exposure and glyphosate treated groups after 30 days exposure in comparison with the control group, these data were agreed with McMullin et al. (2004) and Vaughan et al. (2000). Estrogens often called "female" sex hormones that regulate the development of sex characteristics and the menstrual cycle and help maintain pregnancy. Recent study of (Thongprakaisang et al., 2013) showed that glyphosate actively bound estrogen receptors, disrupted steroid hormone biosynthesis and also potentially modulated the biological effects of estrogens via alterations in the expression of estrogen receptor 1 (esr1), the predominant estrogen receptor in the ovary. The normal female reproductive cycle is initiated and regulated by the hypothalamic-pituitaryovarian (HPO) axis (Downey, 1980). Hormonal irregularity results in disturbance in the estrous cycle with distinct morphological changes in the female reproductive organs as observed in our results. The decrease in serum estrogen level following exposure to atrazine ( $15 \& 30$ days) or glyphosate ( 30 days) may attributed to ovaries affections including disappearance of any stage of growing follicles, presence of multiple cystic and atretic follicles and degeneration or complete lysis of the oocyte, pyknotic and sloughed granulosa cells as well as numerous degenerated cells that present in the antrum. The obtained results are in accordance with that recorded by Hiroshi et al. (2009). Therefore, the deleterious effect that recorded in ovarian tissue reflected on the uterine tissue including degenerated and pyknotic endometrial surface epithelium, atrophied endometrial glands, infiltrated inflammatory cells in the endometrial stroma. These affections were confirmed also by weak to negative expression of VEGF in both ovarian and uterine sections. VEGF expression in uterine tissue of rats is regulated by estrogens (Cullinan-Bove and Koos, 1993). Negative VEGF expression results in decreasing in ovarian and uterine angiogenesis and microvascular permeability. Defects in angiogenesis may contribute to a variety of disorders including anovulation, infertility, pregnancy loss, ovarian hyper stimulation syndrome and ovarian neoplasms (Geva and Jaffe 2000). In the present study the serum progesterone levels was decreased significantly in atrazine treated groups ( $15 \& 30$ days) and glyphosate (30 days) after exposure in comparison with control group, these data were in correlation with Hiroshi et al. (2009) who mentioned that female rats exposed to atrazine $100 \mathrm{mg} / \mathrm{kg}$ bw for 4 weeks showed significant decrease in serum progesterone. These observations are in coincided with our histological alterations and immunohistochemical results as regarded by absence of any newly formed corporal lutea. Moreover, anovulatory effect of atrazine as well as endocrine dysfunction after glyphosate exposure were recorded (Hiroshi et al., 2009 and Vaughan et al., 2000). The latter authors reported that exposure to glyphosate causes endocrine dysfunction and also reduces the synthesized mRNA. It was also reported that damage to the ovaries, progesterone and estrogen levels are reduced. Estrogen and progesterone naturally affect fertility and ovulation under the control of LH and FSH secretion from the pituitary gland (Ralph et al., 2000). Potent endocrine disruptors typically cause histological changes in the ovary and uterus which induces ovarian atrophy in association with hyperplastic and hypertrophic changes in the uterus (Greaves, 2007). Natural recovery from glyphosate after 15 days cessation of administration showed that the estrogen and progesterone returned to its normal level that may be due to the improvement that was seen in the ovarian and uterine sections which became similar to the control group with intense positive VEGF immunoreactivity. On contrary to the results of Williams et al. (2000) who stated that there were no adverse effects in reproductive tissues from animals treated with glyphosate in chronic and/or subchronic studies. While our results indicated that the prolonged exposure for glyphosate may induce deteriorative effect in the ovary and uterine tissues. While in case of atrazine the estrogen and progesterone levels remain significantly decreased even after stoppage of exposure that may attributed to mild improvement was noticed in the examined ovarian and uterine sections. The endometrial stromal and endothelial cells were VEGF moderately reacted while the endometrial surface and glandular epithelial cells still exhibited weak to negative immunoreactivity. Accordingly, the present results demonstrate that prolonged exposure to atrazine can induce infertility and impair folliculogenesis, alter estrus cyclicity as well as uterine dysfunction. These 
data are in agreement with Wirbisky and Freeman (2015) and Laws, et al. (2000).

\section{CONCLUSION}

From the current study, it can be concluded that, glyphosate had less deteriorated effect on fertility parameters and morphological changes of reproductive organs of the exposed female rats than atrazine as well as the natural recovery rate after withdrawal is higher in glyphosate than atrazine.

\section{REFERENCES}

All Life In a Viable Environment "ALIVE" (1973): Law for the humane treatment and management of animals (Law No. 105, October 1, 1973, revised December 22, 2000) in Japan.

Bancroft, J. and Cook, H. (1994): Immunocytochemistry. In: Bancroft JD Cook HC, Turner DR, editors. Manual of histological techniques and their diagnostic applications. 2nd Ed. New York: Churchill Livingstone; 1994. pp. 263-325.

Bancroft, J. and Gamble, M. (2008): "Theory and practice of histological techniques. 6th Ed., Churchill-Livingstone, Edinburgh, London, Melbourne, New York.

Battaglin, W.; Kolpin, D.; Scribner, E.; Kuivila, K. and Sandstrom, M. (2005): Glyphosate, other herbicides and transformation products in Midwestern streams, 2002. J. Am. Water Resour. Assoc. 41, 323-332.

Chan, C.; Joel, F. and Mahler, D. (1992): National toxicology program (NTP) Technical report on toxicity studies of glyphosate. United States Department of Health and Human Services.

Cullinan-Bove, K. and Koos, R. (1993): Vascular endothelial growth factor/ vascular permeability factor expression in the rat uterus: rapid stimulation by estrogen correlates with estrogen-induced increases in uterine capillary permeability and growth. Endocrinology, 133, 829-837.

Demirm, R.; Kayisli, U.; Cayli, S. and Huppertz, B. (2006): Sequential steps during vasculogenesis and angiogenesis in the very early human placenta. Placenta; 27(6-7): 535-539.

Downey, B. (1980): Regulation of the Estrous Cycle in Domestic Animals. A Review Canad. Vet. $\mathrm{J}$.

EPA, U.S. (2011): Pesticides Industry Sales and Usage: 2006 and 2007 Market Estimates; U.S. Environmental Protection Agency: Washington, DC.

Foradori, C.; Hinds, L.; Hanneman, W.; Legare, M.; Clay, C. and Handa, R. (2009): Atrazine inhibits pulsatile luteinizing hormone release without altering pituitary sensitivity to a gonadotropin-releasing hormone receptor agonist in female Wister rats. Biol. Reprod. 81(1): 40-45.

Frost, A.; Sparks, D. and Grizzle, W. (2000): Method of antigen recovery vary in their usefulness in unmasking specific antigen in immunohistochemistry. Applied immunohistochemistry Mol. Morph.8 (3): 236-243

Geva, E. and Jaffe, R. (2000): Role of vascular endothelial growth factor in ovarian physiology and pathology. Fertil. Steril. 74, 429-438.

Greaves, $P$. (2007): Female genital tract. In: Histopathology of Preclinical Toxicology Studies (3rd ed), Elsevier, 717-779.

Hiroshi, S.; Takashi, K.; Yasuhiko, S.; Tomohiko, H.; Tsutomu, K.; Makoto, U.; Hydieuk, T.; Seitarou, I. Yasuhiro, Y. and Seishi, O. (2009): Collaborative work in evaluation of ovarian toxicity two or four week repeated dose studies and fertility study of atrazine in female rats. Journal of toxicological science, Vol.34, special Issue 1, SP147-S.

Kamat, B.; Brown, L. and Manseau, E. (1995): Expression of vascular permeability factor/vascular endothelial growth factor by human granulosa and theca lutein cells. Role in corpus luteum development. Am J. Pathol; 146: 157-65.P155.

Lasserre, J.; Fack, F.; Revets, D.; Planchon, S.; Renaut, J.; Hoffmann, L.; Gutleb, A.; Muller, C. and Bohn, T. (2009): Effects of the endocrine disruptors atrazine and PCB 153 on the protein expression of MCF-7 human cells. J. Proteome Res; 8: 5485-5496.

Laws, S.; Ferrell, J.; Stoker, T.; Schmid, J. and Cooper, R. (2000): The effects of atrazine on female Wister rats: An evaluation of the protocol for assessing pubertal development and thyroid function. Toxicol. Sci., 58, 366367.

Marcondes, F.; Bianchi, F. and Tanno, A. (2002): Determination of the estrous cycle phases of rats: Some helpful considerations. Brazilian Journal of Biology, 62: p. 609-614

Mc Mullin, T.; Andersen, M.; Nagahara, A.; Lund, T.; Pak, T.; Handa R. and Hanneman, W. (2004): Evidence that Atrazine and diaminochlorotriazine inhibit the estrogen/progesterone induce surge of Luteinizing hormone in female SpragueDawley rats without changing estrogen receptor action. Toxicol. Sci. 79, 278-286.

Modlich, U.; Kaup, F. and Augustin, H. (1996): Cyclic angiogenesis and blood vessel regression in the ovary: blood vessel regression during luteolysis involves endothelial cell detachment and vessel occlusion. Lab Invest; 74: 771-80. 
Nardo, L. (2005): Vascular endothelial growth factor expression in the endometrium during the estrual cycle, implantation window and early pregnancy. Curr. Opin. Obstet. Gynecol; 17(4): 419-423.

Ralph, L.; Tammy, E.; Lee, T.; Jerome, M. and Keith McElroy, W. (2000): Atrazine Disrupts the Hypothalamic Control of Pituitary-Ovarian Function. Toxicological sciences. 53, 297307.

Schonbrunn, E.; Eschenburg, S.; Shuttleworth, W.; Schloss, J.V.; Amrhein, N.; Evans, J. and Kabsch, W. (2001): Interaction of the herbicide glyphosate with its target enzyme 5enolpyruvylshikimate 3-phosphate synthase in atomic detail. Proc. Natl. Acad. Sci., 98(4), 1376-1380

SPSS (2007): Statistical software package for the social science. SPSS Inc. United State of
America. Inc., Chicago, IL. Cited by http://www.spss.com.

Thongprakaisang, S.; Thiantanawat, A.; Rangkadilok, N.; Suriyo, T. and Satayavivad, J. (2013): Glyphosate induces human breast cancer cells growth via estrogen receptors. Food Chem. Toxicol., 59, 129-136.

Vaughan, T.; Ryan, J. and Czaplewski, N. (2000): Mammalogy, sauders college Publishing, $4^{\text {th }}$ Ed., 20, 340-341.

Williams, G.; Kroes, R. and Munro, I. (2000): Safety Evaluation and Risk Assessment of the Herbicide Roundup and Its Active Ingredient, Glyphosate, for Humans Regulatory Toxicology and Pharmacology 31, 117-165.

Wirbisky, S. and Freeman, J. (2015): Atrazine Exposure and Reproductive Dysfunction through the Hypothalamus-Pituitary-Gonadal (HPG) Axis. Toxics 3, 414-450.

\title{
تأثير الأترازين والجلايوفوسات على الجهاز التناسلي الأتثوي في الفئران :دراسات نسيجيه ونسيجيه كيميائية مناعية

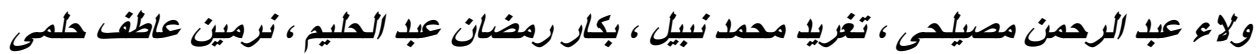

E-mail: tagh_mhm@yahoo.com_Assiut University web-site: www.aun.edu.eg

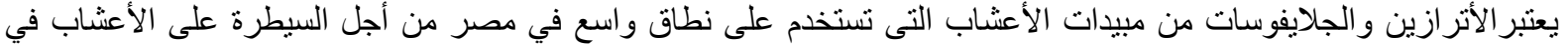

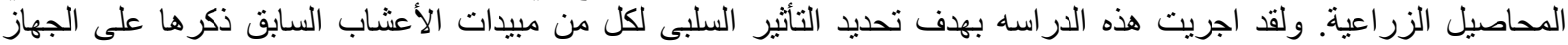

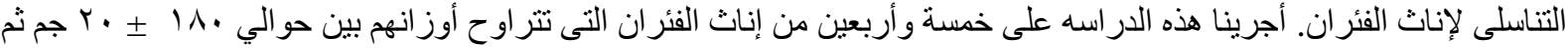

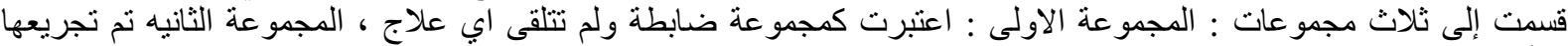

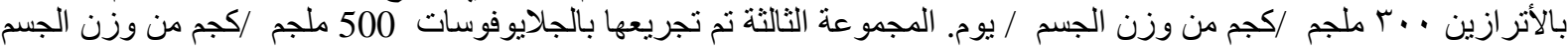

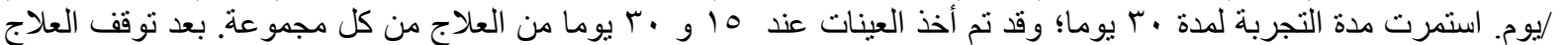

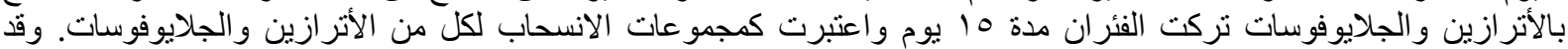

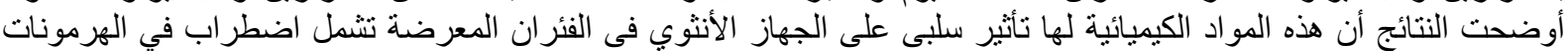

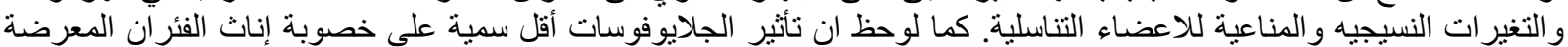

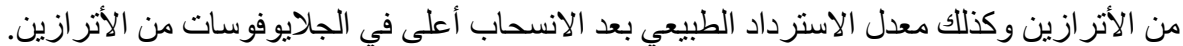

